\title{
Reprocessed Code
}

National Cancer Institute

\section{Source}

National Cancer Institute. Reprocessed Code. NCI Thesaurus. Code C93654.

A coded value specifying whether a product is reconditioned. 